\title{
ANALYZING FINANCIAL STRUCTURE OF TURKISH HEALTHCARE SYSTEM IN COMPARISON WITH U.S., GERMAN, BRITISH, FRENCH AND CUBAN HEALTHCARE SYSTEMS
}

DOI: 10.17261/Pressacademia.2015414364

\author{
Mustafa Isik', Fikriye Isik2, Mithat Kiyak ${ }^{3}$ \\ ${ }^{1}$ Medicalpark Health Group. mustafa.isik@mlpcare.com \\ ${ }^{2}$ Dr.Lutfi Kırdar Training and Research Hospital. fikriye.isik@sbkeah.gov.tr \\ ${ }^{3}$ Okan University. mithat.kiyak@okan.edu.tr
}

\section{Keywords \\ Healthcare service finance, financial analysis of healthcare system, healthcare finance models, comparison of healthcare systems. \\ JEL Classification F50, H51}

\begin{abstract}
Financial structure of healthcare systems and the share reserved for healthcare expenses are regarded by countries as very important indicators of economic development. Healthcare expenses are, therefore, among most important agenda items for healthcare policy makers. Finance of healthcare services is still a heated debate item in both public and private sector. Negative economic conditions, fiscal deficits and pressures imposed by international credit institutions all lead to mobilization of private sources for public expenditures and market-based financing model in healthcare sector. All states aim equal access to quality and efficient healthcare services at service delivery phase, irrespective of the method adopted. Healthcare services should be quality and accessible by all citizens in order to realize the "right of healthy life". Healthcare services should be, therefore, efficiently and effectively financed. Aim of this study is to address and analyze methods used in financing Turkish healthcare services and to compare thereof with financial structures of U.S., U.K., France, Germany and Cuba, which represent distinctive healthcare finance models worldwide. In this end, active applications in Turkey are reviewed by addressing pros and cons of Turkish healthcare finance model in comparison with other systems.
\end{abstract}

\section{INTRODUCTION}

A healthcare service is among most important socio-economic development indicators of countries. Principal aim of health services is to provide affordable healthcare services at quality level acceptable to receiver whenever required. Although financing models of healthcare services vary from one country to the other, variations are also observed in payment methods, organization type and rules for access to service, even if same financing method is used.

Scientific and technological advancements accelerated evolution of medicine, resulting with increased quality of healthcare services. However, recent increase in incidence of chronic and degenerative disease secondary to improved living conditions is accompanied 
by costs which are hardly met. While fight against contagious disease is usually an important source of finance in developing countries, financing cost of managing elder population with chronic disease, which requires costly treatments, is recently gaining an important share from the budget. Scientific and technological dependence of developing countries to developed countries emerges necessity to address new health organization models. (Ener, M.,Yelkikalan, N. 2003)

Financing problems take the lead in troubles experienced in healthcare sector. This problem applies both developed and developing countries, but economic implications may vary in each country. There are two principal methods in financing of healthcare services; direct finance and indirect finance. Direct financing method implies healthcare receivers pay the service fee out of the pocket. Services produced by public and private sector are purchased and paid by the consumer. On the other hand, for indirect financing method, a third party payer takes place between service provider and receiver. Healthcare system is financed by healthcare system, uniform taxes, special taxes, consumer contributions and donations.

Principal aim of this study is to clarify dominant healthcare financing method in Turkey by analyzing healthcare financing models preferred by countries and to compare this model with healthcare system financing methods in the U.S., U.K., Germany, France and Cuba, which use divergent models among all healthcare systems worldwide. It also aims to reveal out pros and cons in terms of economic parameters of a state by analyzing financial structure of healthcare system. In this end, primary healthcare financing models will be addressed and applications adopted in each country will be compared. Next, application methods of those models will be addressed and analyzed.

\section{HEALTHCARE SYSTEM FINANCING METHODS}

Many divergent dynamics should be taken into consideration when healthcare system financing model of a country is determined. It is probable to reveal different outcomes for each model. One should always remember that there is no unique model, which delivers perfect outcomes for both society and financing system, each model is accompanied by unique advantages and disadvantages and a model, generating substantially good outcomes in a country, may not produce same outcomes in another country totally due to factors originating from this second country. (Tatar, M. 2011)

It is necessary to mention about three principal healthcare financing models before we address healthcare system financing methods. In principal, there are three basic models; Beveridge Model, Bismarck Model and private health insurance. Those models vary substantially in terms of source of finance, decision-making mechanisms and organization of service providers.

Various characteristics of those models are briefly given in the table. (Tatar, M. 2011) 
Table 1: Health System Models

Source: Wild and Gibis (2003)

\begin{tabular}{|c|c|c|c|c|}
\hline MODELS & $\begin{array}{c}\text { Beveridge Model } \\
\text { (United Kingdom) }\end{array}$ & $\begin{array}{c}\text { Bismarck Model } \\
\text { (Germany) }\end{array}$ & $\begin{array}{c}\text { Private Insurance } \\
\text { Model } \\
\text { U.S.A. }\end{array}$ & $\begin{array}{c}\text { Socialist Model } \\
\text { Cuba }\end{array}$ \\
\hline $\begin{array}{c}\text { Decision } \\
\text { making } \\
\text { mechanism }\end{array}$ & $\begin{array}{c}\text { Decision making } \\
\text { and management } \\
\text { by government }\end{array}$ & $\begin{array}{c}\text { Decision making and } \\
\text { management by } \\
\text { insurance fund and } \\
\text { physician associations }\end{array}$ & $\begin{array}{c}\text { Principles of } \\
\text { private } \\
\text { entrepreneurship }\end{array}$ & $\begin{array}{c}\text { Decision making } \\
\text { and management } \\
\text { by government }\end{array}$ \\
\hline Resources & Taxes & $\begin{array}{c}\text { Contributions of } \\
\text { employees and } \\
\text { employers }\end{array}$ & Private financing & $\begin{array}{c}\text { Government } \\
\text { budget }\end{array}$ \\
\hline $\begin{array}{c}\text { Healthcare } \\
\text { service } \\
\text { providers }\end{array}$ & Public & Public/Private & Private & Public \\
\hline
\end{tabular}

Since Beveridge model emerged in the U.K. following Second World War, it is generally identified with National Health Service (NHS) of the United Kingdom. Today, this model is used by Denmark, Finland, Ireland, Spain, Sweden, Italy, Norway, Portugal and Greece and it is principally characterized by financing healthcare services with taxes. Other features are as follows; government controls healthcare system financing through the budget; all citizens have free-of-charge access to healthcare services, excluding contribution shares; physicians are paid a salary or a fee per patient in return for services; organizations use budgets which are determined by central administrative body. (Tatar, M. 2011)

Bismarck Model is first introduced by Bismarck in Germany in 1883 and it is put into force in many countries over time. Although it is also identified with German Healthcare system due to its origin, it is currently used by many developed and developing countries, including Austria, Belgium, France and the Netherlands. It is the most commonly used healthcare financing method due to World Bank's healthcare reform on health policies especially after '90. (Tatar, M. 2011) United States of America is the homeland of private health insurance and it is among healthcare financing models, which are not commonly recommended due to factors written below. (Tatar, M. 2011)

Milton I. Roemer's Healthcare Classification is another well-recognized and commonly used method to classify healthcare systems of countries. Healthcare systems are addressed in four main classes under title "Types of National Health Systems Classified by Economic Level and Healthcare System Policies" in the book titled "National Health Systems of the World":

1. Entrepreneur and Free Health System

2. Welfare-oriented health system

3. General and Inclusive Health System

4. Socialist and Central Planned Health System Policies Group 
One or more than one features of those four main health systems can be observed in a country or it is also possible to see very special applications. A country should be considered in a particular group, if typical features of a system are dominantly or widely used or most part of society takes healthcare services in this way. (Sargutan, A. 2005)

Inclusive Type Health System is also known as Beveridge Model. This system fundamentally adopts the principle of producing all healthcare services for the whole population and of delivering those services free-of-charge by the state. There is always a strong public administration in this system. Private sector gains a small share in service delivery. Although public sector is the principal factor in service supply, private sector may also play a limited role in service offer. All negative outcomes arising from service offer by private sector are minimized by a well-regulated audit system. United Kingdom, Norway and Italy are some examples for this type of health system. We will address U.K. sample among those states.

For Free Market Type Health System, private sector is the principal factor for both service supply and request. Healthcare service request is funded by out-of-pocket payments and private insurances. The wealthy one will have health coverage. Private sector regulates the service supply in this system. U.S. and Brazil are examples of states where this system is adopted. We will try to review the U.S. sample among those states.

Welfare-oriented Health Systems are also referred as Bismarck Model. This social securitybased model is funded by premium incomes. Healthcare supply covers both public and private sectors. The principle of this system is covering all citizens under mandatory health insurance, which is funded by semi-direct personal premium payments. Germany, France and Belgium are examples of those states. Here, we will address Germany sample. Socialist Type Health System is characterized by offering preventive and therapeutic healthcare services free-of-charge to all citizens. Private sector plays no role in healthcare service delivery. Healthcare service delivery is completely managed by public authorities. U.S.S.R. and Cuba are examples of this system. We will review Cuba sample.

Same groups emerge in both healthcare system classification models. Selection of healthcare financing method in a state reflects social values and policy aims of that state. In the light of those classifications, Healthcare System Financing involves methods written below.

\subsection{Tax-Based Financing}

Tax-based financing, also known as Beveridge Model, implies collecting taxes from citizens and allocating resource to various sectors from the common resource pool. For tax-based financing system, citizens makes personal contributions to healthcare system through tax payments and no extra fee is paid for use of healthcare services, excluding contribution fees mandated by the system. Recently, 13/29 OECD states are substantially financed by taxes. Tax collection capacity and equity of taxes collected are critical questions to be answered for this type of financing. High taxation rates not only decreases motivation to get higher income, but it may also pose negative influence on international competitive capacity and investment potential of the state. (Tatar, M. 2011) 
Economic recession is among critical periods to the tax-based financing method. Recession is accompanied by reduced production, resulting with lower income and new taxes put into force or increasing taxation rates - all undesired political outcomes, and thus, cost limitation is more commonly discussed in healthcare sector, as valid in all other sectors, and the question "who utilizes healthcare services" is more frequently asked. (Evans, 2002).

\subsection{Out-of-Pocket Payments}

This type of payment is reserved for services not covered by social security or if access to service is challenging due to long waiting periods. Such payments are usually made to private sector service providers, including but not limited to dentists and laboratories. Out-of-pocket payment implies all payments made by patients or family members to benefit from healthcare service. (Uğurluoğlu, E; Özgen, 2008)

Although out-of-pocket payment is seen in almost all health systems, it is, alone, not a proper healthcare financing method, since time, location and actual cost of healthcare service are unknown. Payments in this category are made directly by citizens to purchase a good or a service, which is not reimbursed by state or a third party payer.

For healthcare system, out-of-pocket payment should be a financing method, which is reserved solely for compulsory cases and is related with income status of the citizen, if possible. Some exemptions are put into force in order to minimize negative outcomes of users' contributions to healthcare systems; when some state examples are reviewed, it is observed that chronic diseases such as hypertension and diabetes, cancer therapies and citizens with lower income - in some countries, are granted exemption. (Tatar, M. 2011)

\subsection{Private Health Insurance}

Private health insurance, a profit-oriented financing method, undertakes different roles in different states. Private health insurance plays 5 different roles according to the classification made by World Health Organization: dominant, mandatory, substituting, supplementary, and complementary. For example, private health insurance is obligatory for all employed citizens in the U.S. (Dominant). It is mandated for all citizens in the Switzerland. It is bought by persons, who are partially or completely excluded from public health insurance programs or are wealthy enough to get out of the public health insurance program in the Netherlands, Belgium and Germany (substitute private health insurance). It is bough, in Canada, France and Italy, for services not covered or partially covered by public health insurance programs (supplementary insurance). In the Finland, Greece and the U.K., it is bough to enjoy extended service provider spectrum, although same healthcare service is covered by public healthcare programs. (Complementary private insurance) (Uğurluoğlu, E; Özgen, 2008)

For this financing system, healthcare costs are reimbursed by private insurance company and individual person or an organization has health risks insured. Similar to out-of-pocket financing model, private health insurance is among financing methods which should not be used on large scale due to many reasons. This method can be used at different levels and for divergent purposes. It is the principal healthcare finance organization for most citizens in some states (U.S.), whereas it supplements public systems in other states. In 
other words, private health insurance is used to finance services which are not covered by public programs.

\subsection{Social Health Insurance}

Social health insurance, also known as Bismarck model, is developed in Germany. When healthcare services are financed by social health insurance, both employee and employer pays a premium, proportional to the income of the person, subject to pre-determined rules; those premiums are collected in a pool and healthcare services are used by citizens who need healthcare, while costs are financed from the pool. There are inter-state variations in terms of amount of social health insurance premiums, number of organizations collecting premiums and reimbursing costs, organization and type of healthcare service delivery. (Normand and Busse, 2002):

Continuous and foreseeable finance is among most importance advantages brought by financing healthcare services with social health insurance. Details on employment policies and population growth of a state enable one to foresee future social insurance income and expenditures and to make short-, mid- and long-term projections on amount of premiums to be collected through social health insurance programs. Those projections generate information, which is extremely valuable for those who plan healthcare services, and this knowledge facilitates sustainable policies for both delivery and finance of healthcare services. The most negative aspect of social health insurance is poor coverage of employees of agriculture and informal sectors and other challenges to the cost controlling. (Tatar, M. 2011)

\section{Health Finance Structures in Various Countries}

There are various healthcare systems worldwide. There are inter-state healthcare system variations. Therefore, there is no single healthcare system, which is identically used by more than one state. Healthcare systems vary depending on political, ideological and religious orientations, rather than economic condition and geographical localization. International finance actors play direct or indirect role on orientations of states. Wealth or higher share of healthcare expenditure in overall budget do not necessarily imply that healthcare system is well organized, resulting with a very good level of health. U.S. is the best example. Considering states with good health level indicators, organization is dominated by primary healthcare and financing is largely undertaken by governments or social security systems. In this context, healthcare systems of countries, which form the sample of this study, will be addressed in order to analyze financial structure of healthcare systems.

\subsection{Healthcare System of the United States}

For the United States of America, we see a model, which is largely based on private healthcare insurance organizations and is largely finances by private health insurance. Most citizens have a private health insurance policy. Service is commonly delivered by private healthcare facilities and self-employed physicians. Primary healthcare organization is not very strong and healthcare expenditure per capita is substantially high. Share of healthcare expenditures in GNP is at rate of 16.5 percent. This rate is approximately two folds the mean rate in OECD states. Health indicators of the state are not consistent with 
healthcare expenditure despite presence of extremely prestigious diagnosis and therapy centers and the importance attached to the research. Although healthcare expenditure rate is notable in the U.S., a significant portion of the population has no health insurance, even coverage for primary healthcare. The U.S. government put into force two programs in order to overcome this problem. These are Medicare and Medicaid programs, which cover healthcare expenditures of retirees and citizens with low income. Either of those two programs is an example of public finance in the U.S. health system, which is grossly based on private finance. (Bekçi, ì. 2011)

Medicare (Medical Insurance): All citizens aged $<65$ years are spontaneously covered by Medicare in the U.S., irrespective of income level or wealthy status. There are two payment plans, including Medicare $A$ and $B$. Medicare $A$ reimburses hospitalization costs (inpatient therapies), while Medicare $B$ reimburses physician and nurse care, outpatient therapies and laboratory costs. The most significant drawback of Medicare services is that all expenditures are not covered. (www.muglahsm.gov.tr/websayfalar/ailehekimligi/.../dunyasagliksystem). Medicare is a federal program, which is financed by Social Security Administration that offers a national pension system and other benefits. Medicare is put into force to fight against poverty and it is a type of health insurance, which is rather supported, financed and administered by federal government.

Medicaid (Medical Assistance Insurance): Citizens or families with annual income below a pre-determined level are covered by Medicaid. Medicaid provides coverage to approximately $10 \%$ of the population. It is financed by general taxes collected by federal government and state governments. Therefore, Medicaid is valid in all states, similar to Medicare. However, states act autonomously in determining annual income level - the threshold- and coverage of Medicaid expenditures. Medicaid is a common federal - state program and offers medical care to poor people.

The U.S. is the best example for the principle "finance is not the only determinant of health". It is important to use current resources in a rational, fair, equal and productive manner. Hence, Barack Obama, the U.S. President, announced a health reform in order to overcome problems of current healthcare system. This plan aims to cover approximately 31 million American citizens, who have no health insurance or coverage, widen extent of medical prescriptions and increase federal subsidies, which support citizens gain a health insurance policy. (Çiftçi, H.i..; 2011)

The most remarkable outcome of the U.S. model is the extremely high cost, but health indicators of the state are too far to be good despite the high cost. Healthcare resources are allocated to secondary and tertiary care, which is relatively expensive, and nonprofitable primary care facilities do not attract interest of private sector; citizens with limited access to expensive secondary and tertiary healthcare is deprived of cost-effective primary care services, since primary healthcare services are poorly organized by public authorities. (Bekçi, í. 2011)

\subsection{British Healthcare System (Beveridge Model)}

W.Beveridge, a congressman, was assigned in 1941 to issue a report for establishing a Social Security System and his report is the basis of British social security and health 
system. Therefore, this system is referred as "Beveridge System". Ireland, Island, Sweden, Norway, Finland, Portugal and New Zealand are examples of states which finance healthcare services with this system. (Çiftçi, H.i.; 2011)

National Health Service (NHS) was established in 1948 with a regulation issued by the U.K. government in 1946. NHS offers free-of-charge healthcare service to all British citizens, or briefly, all people living in the U.K. (Çiftçi, H.i..; 2011)

Today, British health system is completely financed by general taxes. It is aimed to maximize competition and efficiency with reform acts, which were started in 1991. However, taxes are still principal finance source of the NHS. Arguments are ongoing on the role of the state and accordingly of public authorities and efficient use of resources. Expectations of citizens and drawbacks of the system are all important problems, which need to be resolved by decision makers. (Mutlu and Işık, 2002, p.262)

Health system uses a substantial portion of economic sources. Healthcare expenditures are financed by government's budget at rate of $82.2 \%$, taxes collected for consumer goods at rate of $10 \%$ and contributions of patients at rate of 7.8 percent. British health system is still cheaper than that of other states, despite negative attitudes of reforms. British healthcare expenditures are below average of European Union and OECD.

\subsection{German Healthcare System (Bismarck Model)}

German Health system is also referred as Bismarck System. The aim is to provide citizens with possible widest-spectrum healthcare services. Service delivery means are largely possessed by public authorities. Healthcare service delivery is substantially financed by social insurance system. Current system was established in 1950's. In early 2000, more than 100 states worldwide reconstructed healthcare systems and adopted this system. (www.muglahsm.gov.tr/websayfalar/ailehekimligi/)

Persons covered by this system pay health insurance premium, which is proportional to the income status. Employer also pays a premium on behalf of employee in this system, which projects risk share and advance payment. This health insurance is referred as "Krankenhassen" in German language. Baseline service coverage is narrow in Germany. Additive insurance packages are bought even in current system. (www.muglahsm.gov.tr/websayfalar/ailehekimligi/)

Germany applies a mixed healthcare financing system. In this system, disease insurance funds are represented by autonomous organizations, which are administered independent from the government. Almost all citizens are covered by health insurance in Germany. (Mutlu and Işık, 2002, p.268)

Germany is deemed among countries with strongest healthcare systems worldwide. It plays also a pioneering role in public health insurance business. Everybody have access to healthcare services in a large network, which is comprised of hospitals, physician offices and other healthcare facilities (www.muglahsm.gov.tr/websayfalar/ailehekimligi/).

Ninety percent of all citizens have social security registration and pays a premium at a predetermined amount every month. A part of population is either covered by private insurance or a private insurance in addition to public insurance program. However, we can 
speculate that German health system is under high debt secondary to aging population and increased birth rate.

Germany shares $10.8 \%$ of GNP to healthcare expenditures and this rate is above average (7.9\%) of OECD countries. Public share in total German healthcare expenditures is 74.9 percent. Of this, $16.6 \%$ is funded by central budget and rest is financed by social security funds. Of public healthcare expenditures, 97 percent is allocated to current expenditures and only $3 \%$ is reserved for investment. Therefore, it is hard to mention that the state makes a significant investment to the healthcare sector. Private healthcare expenditures account for $25.1 \%$ of total healthcare expenditures. Out-of-pocket expenditures make $42.4 \%$ of private healthcare expenditures. Of total healthcare expenditures, private health insurance expenditures accounts for $7 \%$, out-of-pocket expenditures accounts for $7 \%$ and social security program expenditures account for 3 percent. (Çetin,R.20012)

\subsection{French Healthcare System}

French Healthcare system is characterized by a national social insurance system, which is financed by taxes and supported by optional disease insurance. General health insurance, general disease insurance and family physician practice are put into force in 1974, 2000 and 2006, respectively, in France. General health insurance, adopted in 2000, covered $99 \%$ of the population. Thus, people with income status below a particular level are taken under insurance coverage. Everybody with residence permit is covered by general disease insurance in France. (www.istanbul.edu.tr, 2011)

Almost all citizens are covered by social health insurance in France. Demand financing method is based on insurance premium. Of the population, $74 \%$ is covered by National Health Insurance Fund, $7 \%$ by insurance fund established by agriculture employees, $9 \%$ by funds of employers, $6 \%$ by funds managed by Ministry of Health and $2 \%$ by funds managed by private organizations. Subject pays all charges of healthcare services. Next, $75 \%$ of the payment is reimbursed by relevant fund. (www.muglahsm.gov.tr/websayfalar/ailehekimligi/)

The basic principle is that all healthcare expenditures covered by social security are reimbursed by Social Security Administration and National Health Insurance Program. All insurance plans of French healthcare system are established on common principles. Those plans create own resources based on premiums mandatorily paid by the insured employee and employer. Amount of this mandatory premium is calculated with references to services preferred by the insured employee.

France is the leader country of European Union in terms of share of GNP reserved for healthcare expenditures (9\%). France varies from other EU countries by allocating greater resource to inpatient expenditures and less resource to preventive care.

World Health Organization selected French Health System as the best healthcare system in 2000. A good balance is achieved between liberalism and obligation, audit and tolerance and centralism and autonomy. Each government offered a bill of law on finance of social security to the parliament every year since 1996. Thus, targets of disease insurance expenditures for next year are determined. Ministry of Health plays a significant role in this regulation. 
Primary and secondary healthcare services are delivered by family physicians, selfemployed physicians, dispensaries, hospitals and home care facilities. Inpatient care is given by state and private hospitals. Dispensaries and hospitals are administered by local authorities. Healthcare of poor people is largely undertaken by dispensaries, which are managed by municipalities and foundations. (Türk, 2007, p.7)

According to WHO and World Bank data, public healthcare expenditures of France accounts for approximately $79 \%$ of total healthcare expenditures - a figure above healthcare expenditures of Germany and Belgium. Infant mortality rate is low in France $(0.33 \%)$, but maternal mortality is high $(0.8 \%)$.

\subsection{Cuba's Healthcare System}

The principles is to meet all healthcare needs by healthcare facilities, which are commonly possessed by the population, and to include all citizens in common / collective healthcare coverage of the community by using collective resources, which are possessed commonly by population, in healthcare demand and supply. (Sargutan, E, 2005) Following principles are most frequently emphasized in countries which regulate health system according to socialist and central planning rules: Healthcare services are centrally planned and operated; services which are possessed by population are produced according to priorities determined with reference to needs of community; everybody have access to free-ofcharge healthcare services within scope of community-based healthcare coverage (not insurance or security).

Total and per capita share of GNP allocated to healthcare expenditure is high. (10.1\%) Citizens do not need to make any direct or indirect payment, since healthcare service and supply is financed by tremendous resources provided community and the employer government / public authority / community and private sector plays no role. This service is based on primary healthcare system. Primary and preventive healthcare is attached priority and importance and it is integrated to therapeutic services at all levels. (Sargutan, E, 2005)

Health finance is highly decentralized. Public healthcare expenditures are financed by budgets of municipalities at rate of 92.6 percent. Moreover, municipalities meet $82.0 \%$ of education finance and $92.4 \%$ of social welfare finance. Despite recent negative economic conditions, public healthcare expenditures rise regularly, which evidences the political desire of Cuba behind the success of public health system.

Cuba performs very good in the field of health, although it is a developing country. Public targets are realized within a short time after the 1959 Revolution. Low tuberculosis incidence, high vaccination (immunization) rates and low infant mortality rate are all indicators of how efficiently primary healthcare system is operated. Elimination of sewage problem and clean water supply made great contributions to prevention of contagious diseases. It is one of first 30 countries with best healthcare indicators among 180 countries worldwide.

From the perspective of healthcare financing, it is evident that healthcare is completely financed by the state. Public health is free-of-charge and universal. Government claims no charge for preventive medicine measures, diagnostic tests, inpatient treatments and 
inpatient medications, despite substantially limited resources. Rate of out-of-pocket payment is very low. For instance, outpatient medications, hearing aid devices, dental and orthopedic prosthesis and wheel chairs are paid out of pocket. Those services are also free-of-charge for low-income groups. Healthcare facilities are completely public and all healthcare practitioners are wage workers. Ninety percent of total healthcare expenditures are reimbursed by general budget. (Ateş, 2011, p.97)

Some basic indicators provide a basis to evaluate healthcare systems of states. Table 2 shows outcomes for each country when data available are compared with main indicators.

Table 2: Healthcare expenditure in various healthcare systems and comparison with health indicators

\begin{tabular}{|c|c|c|c|c|c|c|}
\hline Country & $\begin{array}{c}\text { Healthcare } \\
\text { expenditure } \\
\text { per capita (\$) }\end{array}$ & $\begin{array}{c}\text { Healthcare } \\
\text { expenditure } \\
\text { (\% of GNP) }\end{array}$ & $\begin{array}{c}\text { Mean life } \\
\text { expectancy }\end{array}$ & $\begin{array}{c}\text { Infant } \\
\text { mortalit } \\
\text { y }\end{array}$ & $\begin{array}{c}\text { Inability to } \\
\text { make } \\
\text { appointment in } \\
\text { same day (\%) }\end{array}$ & $\begin{array}{c}\text { Inability to } \\
\text { afford the } \\
\text { service (\%) }\end{array}$ \\
\hline $\begin{array}{c}\text { Beveridge } \\
\text { countries }\end{array}$ & 3401 & 9,5 & 79,9 & 3,2 & 48,5 & 9,5 \\
\hline $\begin{array}{c}\text { Bismarck } \\
\text { Countries }\end{array}$ & 3345 & 9,1 & 80,7 & 3,4 & 44,0 & 15,5 \\
\hline U.S.A. & 8505 & 17,7 & 78,6 & 6,0 & 70,0 & 33,0 \\
\hline Turkey & 984 & 5,4 & 74,6 & 7,4 & - & - \\
\hline
\end{tabular}

Source: OECD Health Data 2014

Among all countries compared, Turkey shows highest infant mortality rate and maternal mortality rate, as shown in Table 3. Mortality rates in Turkey are also above mean rates of OECD countries. Here, the point is maternal mortality rate in the U.S. and Cuba is above that of countries compared and mean mortality rate in OECD countries. Although life expectancy at birth in Turkey is below mean life expectancy at birth in countries subject to this comparison, it is observed that lifetime increases by comparison years.

\section{Table 3: Life Index of Countries}

\begin{tabular}{|c|c|c|c|c|c|c|c|c|c|c|c|c|}
\hline \multirow{2}{*}{ COUNTRIES } & \multicolumn{4}{|c|}{ Infant mortality rate* } & \multicolumn{4}{|c|}{ Maternal mortality rate* } & \multicolumn{4}{|c|}{ Life expectancy at birth } \\
\hline & 2000 & 2005 & 2011 & 2013 & 2000 & 2005 & 2011 & 2013 & 2000 & 2005 & 2011 & 2013 \\
\hline U.S.A. & 7 & 7 & 6 & 5,9 & 14 & 18 & 21 & 28 & 77 & 77 & 77 & 79,8 \\
\hline GERMANY & 4 & 4 & 3 & 3,60 & 7 & 7 & 7 & 7 & 78 & 79 & 80 & 81 \\
\hline FRANCE & 4 & 4 & 3 & 3,5 & 10 & 8 & 8 & 12 & 79 & 80 & 81 & 82,3 \\
\hline TURKEY & 34 & 22 & 12 & 7,8 & 39 & 28 & 20 & 15,5 & 69 & 72 & 74 & 74,4 \\
\hline $\begin{array}{l}\text { UNITED } \\
\text { KINGDOM } \\
\end{array}$ & 6 & 5 & 4 & 4,2 & 12 & 13 & 12 & 8 & 78 & 79 & 80 & 81 \\
\hline CUBA & 7 & 5 & 5 & 4,2 & 63 & 67 & 73 & 80 & 76 & 78 & 79 & 79,4 \\
\hline OECD, Mean & 11,7 & 9,3 & 7 & 6,5 & 41 & 35 & 33 & 33 & 75,4 & 76,7 & 78 & 78 \\
\hline Worldwide & 52 & 46 & 37 & 35 & 320 & 260 & 210 & 205 & 67 & 68 & 70 & 71 \\
\hline
\end{tabular}

Source: WB, 2007b: 335; WB, 2002: 235; WB, 1996: 215; WB, DATA: HEALTH; WHO,

2012: 52-61; WHO, 2008: 36-45; WHO, 2007: 30 and 76-85; WHO, 2001: 136-143. 
Note: *: Number of babies per 1.000 births dying before age of one, **: Number of mothers dying during pregnancy per 100.000 pregnancies

Considering population growth rate of countries, Turkey demonstrates highest population growth rate (1.16) in comparison with other countries, as shown in Table 4. Population Growth rate is negative in Germany and Cuba, while the rate is below $1 \%$ in the U.S., Germany, France and the U.K.

Table 4: Population Indicators of Countries

\begin{tabular}{|c|c|c|c|c|c|}
\hline \multirow{2}{*}{ Countries } & \multicolumn{4}{|c|}{ Population Growth Rate (\%) } & \multirow{2}{*}{$\begin{array}{c}\text { MODEL / TYPE } \\
\text { Healthcare System }\end{array}$} \\
\hline & 2000 & 2005 & 2011 & 2013 & \\
\hline U.S.A. & 1,1 & 0,9 & 0,7 & 0,90 & $\begin{array}{c}\text { Private Insurance Model } \\
\text { (Free Market Type) }\end{array}$ \\
\hline GERMANY & 0,1 & $-0,1$ & $-0,1$ & $-0,19$ & \multirow{3}{*}{$\begin{array}{c}\text { Bismarck Model } \\
\text { (Welfare-oriented Type) }\end{array}$} \\
\hline FRANCE & 0,7 & 0,7 & 0,6 & 0,60 & \\
\hline TURKEY & 1,5 & 1,3 & 1,2 & 1,16 & \\
\hline DENMARK & 0,3 & 0,3 & 0,5 & 0,23 & \multirow{2}{*}{$\begin{array}{l}\text { Inclusive Type } \\
\text { Beveridge Model }\end{array}$} \\
\hline UNITED KINGDOM & 0,4 & 0,6 & 0,7 & 0,55 & \\
\hline CUBA & 0,3 & 0,2 & 0 & $-0,13$ & $\begin{array}{c}\text { Socialist Type } \\
\text { Healthcare Model }\end{array}$ \\
\hline
\end{tabular}

Source: WB, 2011: 392-393; WB, 2006: 288-289; WB, 2001: 232-233; WB, 1996: 215-216; WB, DATA: HEALTH

\section{FINANCIAL STRUCTURE OF TURKISH HEALTHCARE SERVICES}

Turkish healthcare services have been financed for a long time by different financial resources, which have poor interrelation. In this end, the system is gathered under a single roof after general health insurance system is put into force, and divergent financial resources are substituted by a mechanism, which is comprised of controllable finance resources. General Health Insurance is a world-renowned important health organization model. In this model, healthcare services are largely financed by premiums, which are directly or indirectly collected from users of healthcare services.

Pursuant to Social Security and General Health Insurance Law, which is adopted on May 31, 2006 and put into forced on October 1, 2008, following radical changes are made at finance stage of healthcare services, similar to each stage of healthcare system. First, a larger portion of population is covered by health insurance with general health insurance system and finance of healthcare services is separated from service delivery. Moreover, all social health insurance administrations, which play a role in healthcare financing, are taken under umbrella of General Health Insurance. 33-34).

Within scope of General Health Insurance system, healthcare services are financed by four resources:

- Resources allocated by Social Security Administration, or in other words, taxes paid by employees and employers.

- Resources allocated from central administrative budget, or in other words, taxes. 
- Out-of-pocket payments,

- Resources allocated by private health insurance organizations, or in other words, private health insurance premiums.

Social Security Administration has monopsonist power as the only organization, and it has the power to directly influence decisions on healthcare services and health policies, since it is the principal buyer. The second addressed by social health insurance is who will be covered. A very large portion of population is covered in Turkey and the principle "universal coverage" is adopted. Similarly, limits of the insurance package are also determined on a very large basis. Principles of coverage package are determined by Health Application Announcement (SUT) and rules written on this announcement determine rules of payments by Social Security Administration for each service. (Yıldırım and Yıldırım 2010; 2013).

Share of public healthcare expenditures in the budget is $75.5 \%$, as also shown in Table 5 . However, when health investments are reviewed, only $5.9 \%$ of total healthcare expenditures are allocated to health investment from 2003 to 2013 - the period Turkish Health Transformation Program has been applied. Those investments expenditures are made by Ministry of Health at rate of $57.4 \%$, universities at rate of $12 \%$, other public health authorities at rate of 7 percent and by private healthcare organizations at rate of $23.5 \%$.

Table 5: Share of Public and Private Sector in Total Healthcare Expenditures

\begin{tabular}{|c|c|c|c|c|c|c|}
\hline & Nominal & $\begin{array}{c}\text { Prices valid } \\
\text { in 2013 }\end{array}$ & U.S.D. & SGP USD & \% & $\begin{array}{c}\text { Share in } \\
\text { GNP (\%) }\end{array}$ \\
\hline $\begin{array}{c}\text { Public health } \\
\text { expenditure }\end{array}$ & 444.608 & 612.613 & 287.740 & 475.392 & 75.5 & 42 \\
\hline $\begin{array}{c}\text { Private sector } \\
\text { health } \\
\text { expenditure }\end{array}$ & 144.539 & 209.336 & 95.962 & 157.649 & 24.5 & 1.4 \\
\hline $\begin{array}{c}\text { Total health } \\
\text { expenditure }\end{array}$ & 589.1446 & 821.949 & 383.702 & 633.041 & 100.0 & 5.6 \\
\hline
\end{tabular}

Source: TUIK, Turkish Statistical Institute 2014

When reimbursement methods are taken into consideration, one may see that a mixed method is adopted for reimbursement of healthcare services in Turkey. For instance, Social Security Administration allocates a global budget to reimburse healthcare services offered in hospitals of Ministry of health subject to conditions determined every year and the Ministry distributes the budget among all affiliated hospitals. Same condition applies to medicaments. It is expected that annual medicament expenses fall within a predetermined global budget and new regulations are made, if expenses exceed the budget. Social Security Administration adopts package price for some services or per-service payment for others. Social Security Institution will probably start using payment method according to Diagnosis-related Groups (DRG), which is discussed in Turkey, similar to other 
health system, and partially put into force in hospitals of Ministry of Health, for other healthcare service providers. (Tatar, M. 2011)

When distribution of healthcare expenditures by healthcare service providers is reviewed, healthcare facilities of Ministry of Health make $37.4 \%$ of total expenditure, while the rate is approximately $18.5 \%$ for private hospitals. When review is made with reference to healthcare service providers, 2.1\% of 11 years' GNP - GNPs for Year 2003 to Year 2013, the period Turkish Health Transformation Program is applied - is paid to healthcare facilities of Ministry of Health, 1.6 to privately owned pharmacies to supply retail medicaments, $1 \%$ to private healthcare facilities, $0.5 \%$ to healthcare facilities of universities and $0.4 \%$ to other healthcare expenditures.

Table 6: Total Healthcare Expenditures by Service Providers in 2013 Period (million TL/USD)

\begin{tabular}{|c|c|c|c|c|c|c|}
\hline & Nominal & $\begin{array}{c}\text { Prices valid } \\
\text { in } 2013 \\
\end{array}$ & U.S.D. & SGP USD & $\%$ & $\begin{array}{l}\text { Share in } \\
\text { GNP (\%) }\end{array}$ \\
\hline $\begin{array}{l}\text { Healthcare } \\
\text { facilities of } \\
\text { Ministry of } \\
\text { Health }\end{array}$ & 220.91 & 297.958 & 141.174 & 233.479 & 37.4 & 2.1 \\
\hline $\begin{array}{l}\text { Healthcare } \\
\text { facilities of } \\
\text { universities }\end{array}$ & 51.522 & 71.067 & 33.385 & 55.125 & 8.7 & 0.5 \\
\hline $\begin{array}{c}\text { Healthcare } \\
\text { facilities of } \\
\text { private sector }\end{array}$ & 108.899 & 151.741 & 71.194 & 116.954 & 18.5 & 1.0 \\
\hline $\begin{array}{l}\text { Self-employed } \\
\text { pharmacies }\end{array}$ & 170.254 & 243.256 & 112.005 & 184.980 & 28.9 & 1.6 \\
\hline Other & 38.181 & 57.927 & 25.945 & 42.504 & 6.5 & 0.4 \\
\hline Total & 598.146 & 821.949 & 383.702 & 633.041 & 100.0 & 5.6 \\
\hline
\end{tabular}

Source: Ministry of Health, Ministry of Development, TUIK, Social Security Institution

Pursuant to the new system put into force by Ministry of Health on December 2010 for 310 hospitals, each hospital shall gain a share from the budget, which is proportional to DRG produced for inpatients and corresponding amount of relative values. It is planned to include private hospitals and university hospitals in this system, along with public hospitals. DRG is designed a product produced by hospitals in this system. DRG implies patient groups, which are regulated by codes and define a diagnosis or procedure that has more or less specificity. It is assumed that those groups, which are comprised of patients with similar clinical pictures, consume predictable and similar amount of resources. From this aspect, DRG is regarded as a hospital administration tool.

Health expenditure is recognized among most important development indicator of states. Share of healthcare expenditures in GNP increases parallel to development level of a state. Share of healthcare expenditure in GNP ranges from $8 \%$ to $14 \%$ in developed countries. (Tutar, F.,Kılınç, N.,2007)

In our country, share of healthcare expenditure in GNP is 5.4\% for the Year 2013 - lower than average of OECD countries, 9.3 percent. Distribution of resources by various healthcare services demonstrates that a very limited resource is allocated to preventive 
healthcare services, which has the highest cost effectiveness. Those findings clearly reveal that current Turkish health finance system carries important problems and most of those problems will survive in General Health Insurance system, if relevant measures are not taken. Since finance of Turkish health system is largely based on social insurance principle and it is related with employment, whole population cannot be covered by health insurance. Narrow coverage of unemployment coverage is too far to provide necessary coverage due to high rate of unregistered employment and high unemployment rate. If measures are taken to minimize unemployment and unregistered employment, then General Health Insurance will hardly provide whole population with health coverage. (Yıldırım H.H. 2013)

Table 7: Healthcare Expenditures and Its Share in GNP (2013 (million TL)

\begin{tabular}{|c|c|c|c|c|c|c|c|c|}
\hline & 2007 & 2008 & 2009 & 2010 & 2011 & 2012 & 2013 & $\begin{array}{c}2002-2013 \\
\text { Increase (folds) }\end{array}$ \\
\hline Health expenditures & 50.904 & 57.740 & 57.911 & 61.678 & 68.607 & 74.189 & 84.390 & 3.5 \\
\hline GNP & 843.178 & 950.534 & 952.559 & 1.098 .799 & 1.297 .713 & 1.416 .798 & 1.565 .181 & 3.5 \\
\hline $\begin{array}{c}\text { Share of health } \\
\text { expenditures in GNP (\%) }\end{array}$ & 6.0 & 6.1 & 6.1 & 5.6 & 5.3 & 5.2 & 5.4 & \\
\hline
\end{tabular}

Source: TUIK, Turkish Statistical Institute, 2014

Although very minimal difference is observed for WHO's data on changes in European Region and the EU, notably fluctuating picture is observed in Turkey. Out-of-pocket payments showed a negative inclination from 27.64 in 2004 to 2004 and it started climbing from 2004 to 2006, but it declined again in 2007. The rate is $16.14 \%$ for the Year 2011. (Yıldırım H.H. 2013) Average of Turkey has been above that of the EU since 2008, and averages are equalized as of 2009.

When share of medicament expenditures in total healthcare expenditure is compared with that of OECD countries, the share in Turkey is above the average of OECD countries. This rate is approximately $25.9 \%$ according Year 2013 data. Corresponding figures are 12.6 for the U.S., $15.8 \%$ for the U.K. and $14.8 \%$ for Germany. A report issued by "PricewaterhouseCoopers Türkiye" emphasized that Turkey, the $6^{\text {th }}$ largest pharmaceutics market of Europe, gained notable interest of investors within past 3 years. (Aytekin, S., Aytekin G. 2010)

Medicament expenditures should be well regulated, medicament consumption behaviors of community should be modified and rational medicament use policies should be urgently, efficiently and effectively put into force in order to ensure a sustainable healthcare system. Turkey allocate higher portion of healthcare resources to medicaments in comparison with other countries, since there is less hospital and physician per patient and accordingly, access to healthcare service is far low in comparison with access to medicament. There is an evidence that self-medication is a very common behavior in Turkey. According to National Health Estimates household study, $30 \%$ of patients used over-the-counter medications or medical device. Over-thecounter medications facilitate access to drugs. On the contrary, medicines are delivered only with prescription in OECD countries, which have well structured health systems and regulations. (Liu, Y; Çelik, Y; Şahin B.; 2005) 
It implies to create total income (premium incomes, restructuring, state contribution, supplementary payment, incomes collected from invoices and other incomes) and expenditures (old age pensions, insurance payments, supplementary payments, healthcare expenditures, expenses paid in return for invoice, management, investment and other expenditures) of Social Security Institution. Total income and expenditures of Social Security Institution followed a parallel increase over time. Considering income data for the Year 2013, premium incomes account for most part of Social Security Institution's income. Again, according to data on Year 2013, expenditures are mostly allocated to old age pensions.

When global data of Social Security Institution and personal data of General Health Insurance are reviewed in combination, it is evident that budget deficits of Social Security Institution are remarkably secondary to old age pensions. This are primarily negative outcomes of early retirement, which is a consequence of policies enacted in Turkey in the past, current unemployment and unregistered employment. In the current condition, approximately 2 employees are financing one retiree in Turkey. However, optimal condition is that four employees finance one retiree. In the light of those data, discussions are focused on necessity to narrow principal coverage package of General Health Insurance and to promote citizens buy private supplementary health insurances with reference to the fact that financial sustainability of General Health Insurance is endangered (Yıldırım H.H., 2013). Although significant improvements are made in principal health indicators in last decade in Turkey, those figures are far behind averages of the EU and there are also inter-regional unjust access to healthcare even in the country. Turkey should design and put into force all policies to eliminate inter-regional differences. (Yıldırım H.H. 2013)

Number of admissions to hospitals of Ministry of Health is approximately doubled in last decade, while this increase is three folds for university hospitals and 13 folds for private hospitals. Those figures clearly express that role of private sector strengthened by years. At this point, we should emphasize two principal bias regarding total number of admissions. First one is total number of admission is above the average of Europe and this condition is credited by political actor and healthcare administrators. (Yıldırım H.H. 2013)

\section{CONCLUSION}

Similar to all developing countries, Turkey is among actors who are actually establishing a health policy. International institutions and organizations, including but not limited to WHO, World Bank, OECD, IMF and health technology companies, and supranational organizations, such as the EU, have direct or indirect influences on structure and frame of Turkish health policies. General point of view and guidance of those organizations advocates minimizing contributions made by taxes and premiums by maximizing share of private sector and private insurance business according to market economy.

All discussions advocating necessity to narrow principal coverage package of General Health Insurance and to promote citizens to buy private supplementary health insurances with specific emphasize on negative budget balance of Social Security Institution and with specific reference to endangered financial sustainability of General Health insurance are in fact extensions of shift to private sector-based finance model, as mandated by those 
international organizations. European experiences, and especially German and French experiences do show that marketization of healthcare services, decreasing public share in healthcare sector, increasing share of private sector, tendency to personal payments under contribution share, provoking competition between different healthcare service provider groups and companies, sale of public hospitals to private sector and public private sector partnerships are procedures, which aim decreasing healthcare expenditures.

Although significant improvements are made in principal health indicators in last decade in Turkey, those figures are far behind averages of the EU and there are also inter-regional unjust access to healthcare even in the country. Turkey should design and put into force all policies to eliminate inter-regional differences.

Since finance of Turkish health system is largely based on social insurance principle and it is related with employment, whole population cannot be covered by health insurance. Narrow coverage of unemployment coverage is too far to provide necessary coverage due to high rate of unregistered employment and high unemployment rate. If measures are taken to minimize unemployment and unregistered employment, then General Health Insurance will hardly provide whole population with health coverage.

Discussions on future of social health insurance in Turkey are usually focused on whether "Turkish health system is financed with a system based on taxes" or "Turkish health system is financed with a system based on principles of social insurance". Turkey should prefer continuing social insurance-based financing model in short term, albeit some improvements are urgently required, but tax-based financing method should play a more dominant role in mid- and long-term.

Following improvements should be made in social insurance-based financing model in the short term: The relation between premiums and the service to be used should be eliminated; ceiling premium procedure should be disqualified and new procedures should be put into force to ensure fair and equal finance, such as collecting premiums over total income rather than wage; efficient exemption mechanisms should be developed for outof-pocket payments, which have direct influence on access to service and fair financing; and preventive healthcare services should be prioritized. Those improvements will pave the way to shift from social insurance-model to tax-based financing model. Turkey should make efforts to catch averages of OECD by increasing share of health in GNP in one hand and the country should ensure most efficient use of those resources on the other hand.

\section{REFERENCES}

Armağan, R. (2008), Finance Problem in Healthcare Expenditure and Its Position in Turkish Public Finance in the context of post-1990 Developments.

Aytekin, A. G. Ç., Aytekin, S. (2010). Finance of Healthcare Services and Public Healthcare Expenditures in Turkey. Social Sciences Institute Journal, Gümüşhane University, 1(2).

Bahçe, S., Köktaş, M., Abukan, D. (2012), Healthcare Services Reform and Household Wealth: Turkish Health Transformation Program, Ankara University. 
Celikay, F., Gumus, E. (2010). Health Services and Their Financing in Turkey. Social Sciences Institute Journal, Eskişehir Osmangazi University, 11(1), 177-216.

Ener, M., Yelkikalan, N. (2003). Restructuring and Finance of Health Systems in Developing Countries: Turkish Experience: Social Sciences Institute Journal, Kocaeli University, 6(2), 99-113.

Ersöz, F. (2008). Türkiye ile OECD ülkelerinin sağlık düzeyleri ve sağlık harcamalarının analizi: İstatistikçiler Dergisi 2 (2008) 95-104

Liu, Y., Çelik, Y., Şahin B., (2005), Health and Medication Expenditures in Turkey, Health Administration College, Hacettepe University, Dissertation study.

OECD Health Reviews (2008). A General View of Turkish Health System Before Recent Health Reforms, TürkiyeOECD and IBRD / World Bank

Orhaner, E. (2006), Healthcare Service Financing and General Health Insurance in Turkey, Journal of Trade and Tourism Faculty of Education 1(1).

Sargutan, A. E. (2005). Health Sector and Structure of Health Systems. Hacettepe Health Administration Journal, $8(3)$.

Tatar, M. (2011). Finance Methods of Health Services. Development of Social Health Insurance in Turkey. Journal of Social Security (SGD), 1(1).

Tatar, M., Berman P. (2003), Turkish National Health Estimations 1999, 2000, (Ankara: Ministry of Health , Hygiene School, Manager Office).

Teksöz, T., Helvacıoğlu, K. (2009). Financial Sustainability Analysis of General Health Insurance: What happened in 2009, TEPAV Policy Note.

Tutar, F., Kılınç, N. (2007), Economic Development Potential of Turkey in Health Sector and Comparison with Different Country Models, Afyon Kocatepe University, Journal of Faculty of Economic and Administrative Sciences 9(1).

Uğurluoğlu, E., Özgen H. (2008), Finance of Healthcare Services and Equity. Hacettepe Health Administration Journal, 11(2).

Yavuz, N. (2011). Health systems in Turkey and OECD countries and their comparison (Doctoral dissertation, Social Sciences).

YenimahaHeli, G. Y. (2007), Finance of Health and Healthcare Financing model suggestion for Turkey; Doctoral disseration, Department of Labor Economics and Industry Relations, Social Sciences Institute, Ankara University.

Yıldırım, H. H. (2006), Health Reforms in Turkey: Healthcare Financing Reform and General Health Insurance, EU Society of Health Researches Center, Ankara, < http://www. absaglik. com/sagreform. htm, 21.

Yıldırım, H. H., Yıldıım, T., Erdem, R. (2011), User Contributions in Financing Healthcare Services: A general overview and assessment of situation for Turkey. Journal of Public Administration, 44(2), 71-98.

Yıldırım H.H. 2013, "Health System in Turkey: Health Transformation Program Review Report" Sağlık-Sen Yayınları-21; 2013

YIlmaz, B. E., Y, S. (2011). Role of Official Development Aids in Health , an Universal Public Good, and its Finance. Cost Research Center Conferences, (55).

http://laedrii.blogcu.com/kuba-nin-saglik-sistemi/12904882, Last access:10.02.2015

http://www.muglahsm.gov.tr/websayfalar/ailehekimligi/.../dunyasagliksystem, Last Access:15.03.2015 